\title{
Temperature Field Analysis and Experimental Test of CNC Lathe Precision Spindle System without Load
}

\author{
Lixiu Zhang ${ }^{1, a}$, Qinghua Shi ${ }^{2, b}$ and Yuhou $\mathrm{Wu}^{3, \mathrm{c}}$ \\ Shenyang Jianzhu University, Shenyang 110168, China \\ a851617088@qq.com, b474891749@qq.com
}

\begin{abstract}
Keywords: mechanical spindle ; thermal analysis; temperature field;thermal balance time.
Abstract:The article is based on precision CNC lathe spindle system of the 170CP06 as the research object.The steady and transient temperature field model of the mechanical spindle is established by using the finite element analysis method.As the heat rate for the load and the convective heat transfer coefficient for the boundary conditions for thermal analysis, the temperature field of spindle system is investigated to get the steady state temperature field distribution and thermal balance time of the spindle system.In order to verify the correctness of the model, the thermal experiments without load are executed to the key parts of the temperature of the spindle system at different speeds.Compared with the simulation results, it has a very good agreement with the reliability of the model.And it provides a theoretical basis for controlling the temperature rise of the spindle system.
\end{abstract}

\section{Introduction}

With the rapid development of modern machinery manufacturing technology, the requirements of machine's accuracy are also becoming higher and higher.In the high-speed and precision machine tools, the problem of machining error caused by thermal deformation also has become increasingly serious.A large number of experimental studies show the thermal error is the largest error source of machine tools accounting for $40 \%$ to $70 \%$ in the total error of the machine ${ }^{[1]}$. The spindle is one of the important components of the machine, and its performance affects the overall level of the machine directly.

When the mechanical spindle is working,the internal heat source of the spindle comes form the heat generated by the friction of high-speed rotation's bearing. When the temperature has risen, the relative spatial position and size of the spindle and other parts of the machine will be different from the previous temperature.It will form a different temperature field and produce different degrees of thermal deformation ${ }^{[2]}$. Therefore, the thermal characteristics of research and analysis on the spindle system is crucial to ensure the accuracy of the machine.It is one of the key technologies to be considered in high precision machine tools. The thermal characteristics analysis of the spindle system is to study the distribution of the temperature field.

At present,there are many scholars who study the thermal characteristics of machine tool spindle system at home and abroad.For example,Jin Kyung Choi of South Korea studied thermal characteristics for the spindle and bearing system with the finite element method ${ }^{[3]}$.M.H.Attia from Canada analyzed the whole temperature field of the machine using the finite element method ${ }^{[4]} \cdot \mathrm{Ce}$ Guo and Qinghong Sun from Southeast University have already established a finite element model of the high-speed precision lathe spindle components' temperature field ${ }^{[5]}$.Youwei Hong established the finite element model of the gantry machining center and simulated the temperature field distribution and variation ${ }^{[6]}$.

The article is based on CNC lathe precision spindle system of the 170CP06 as the research object.The temperature field model of the mechanical spindle is established and it is conducted the steady-state and transient thermal analysis of the spindle system. The temperature field of spindle system is investigated to get the temperature field distribution and thermal balance time of the spindle system. The thermal experiments without load are carried out in order to verify the reliability of the model. 


\section{Calculation of the thermal parameters}

The heat source is the foundation of the spindle temperature field research. The heat source of the spindle system includes cutting heat and bearing friction heat.The cutting heat in the machining process is taken away by coolant liquid and swarf.Therefore, the heat source of the spindle may be mainly the bearing frictional heat.

\section{Calculation of the calorific value}

The rolling bearing's heat is mainly generated by the bearing frictional torque. The formula is

$$
H_{f}=1.047 \times 10^{-4} n M
$$

In the formula, $\mathrm{H}_{\mathrm{f}}$ is the calorific value of the bearing; $\mathrm{n}$ is the spindle speed; $\mathrm{M}_{0}$ is the bearing frictional torque.

The bearing frictional torque is the sum of the bearing rolling friction, sliding friction and lubricant friction which have generated to block the bearing running torque.Palmgren ${ }^{[7]}$ deduced the empirical formula which calculates the bearing friction torque. The bearing frictional torque is calculated as

$$
M=M_{0}+M_{1}
$$

In the formula, $\mathrm{M}_{0}$ is related to the viscosity of the lubricant. $\mathrm{M}_{1}$ is related to the load of the bearing regardless of speed.It only considers $\mathrm{M}_{0}$ without load.

Palmgren confirmed the expression using empirical methods:

$$
M_{0}=10^{-7} f_{0}(\vee n)^{2 / 3} D_{m}{ }^{3} \vee n \geq 2000
$$

In the formula, $v$ is the kinematic viscosity of the lubricant in the bearing operating temperature, $\mathrm{mm}^{2} / \mathrm{s} ; f_{0}$ is the coefficient related to the bearing types and lubrication, $D_{m}$ is the average diameter of the bearing, $\mathrm{mm}, D_{m}=0.5(D+d)$.

When the spindle system is analyzed,the thermal load is loaded by the way of bearing the heat rate. The formula is ${ }^{[9]}$

$$
q=\frac{H_{f}}{V}\left(W / m^{3}\right)
$$

In the formula, $\mathrm{V}$ is the volume of the heat source; $V=\pi^{2} D_{m}\left(D_{b} / 2\right)^{2}$, and $\mathrm{D}_{\mathrm{b}}$ is the diameter of the rolling elements.

Calculated by the equation (1) to (5), when the spindle speed is $2000 \mathrm{r} / \mathrm{min}$, we can get the heat rates of the fore and rear bearing to be $342704.4 \mathrm{~W} / \mathrm{m}^{3}$ and $348161.76 \mathrm{~W} / \mathrm{m}^{3}$.

\section{Calculation of the heat transfer coefficient}

According to the heat transfer theory ${ }^{[10]}$, we can know the heat transfer way are the heat conduction, the convection and the thermal radiation,the loss of the radiation heat is less for the spindle system. When we are analyzing the temperature field of the spindle system only to consider the thermal conduction and the convection heat transfer.The thermal conductivity depends on the thermal conductivity of the components in the spindle system. The convective heat transfer is the convection of the spindle surface and the air.The convective heat transfer is formed by driving the rotation of the spindle around the air between the case and the spindle.

The coefficient of the heat transfer depends on the criterion of Nusselt ${ }^{[12]}$

$$
h_{c}=\lambda N_{\mu} / l_{c}
$$

In the formula, $h_{c}$ is the coefficient of the heat transfer; $\lambda$ is the thermal conductivity of the air; $N_{\mu}$ is the coefficient of Nusselt; $l_{c}$ is the feature size.

The Nusselt formula of the forced convection is 


$$
N_{\mu}=0.133 \operatorname{Re}^{2 / 3} \operatorname{Pr}^{1 / 3}\left(\operatorname{Re}<4.3 \times 10^{5} 0.7<\operatorname{Pr}<670\right)
$$

According to Reynolds Criterion, we can know

$$
\mathrm{Re}=u_{c} l_{c} / v
$$

In the formula, Re is the Reynolds number; $\operatorname{Pr}$ is the Prandtl number of the fluid ; $u_{c}$ is the average velocity of the air; $v$ is the coefficient of the air's motion viscosity.

When the spindle rotates by high speed,the average velocity of the air is ${ }^{[13]}$

$$
\begin{gathered}
u_{c}=\pi d n / 60 \\
d=\frac{d_{1} l_{1}+d_{2} l_{2}+\cdots d_{n} l_{n}}{l} \\
l=l_{1}+l_{2}+\cdots+l_{n}
\end{gathered}
$$

In the formula, $d$ is the average diameter of the spindle; $n$ is the speed of the spindle.

Calculated by the equation (6) to (11), when the spindle speed is $2000 \mathrm{r} / \mathrm{min}$, we get each heat transfer coefficients which are $26.6 \mathrm{~W} /\left(\mathrm{m}^{2} \cdot \mathrm{k}\right), 35.63 \mathrm{~W} /\left(\mathrm{m}^{2} \cdot \mathrm{k}\right), 38.3 \mathrm{~W} /\left(\mathrm{m}^{2} \cdot \mathrm{k}\right), 32.5 \mathrm{~W} /\left(\mathrm{m}^{2} \cdot \mathrm{k}\right), 35.2 \mathrm{~W} /\left(\mathrm{m}^{2} \cdot \mathrm{k}\right)$.

\section{Finite element model of the spindle system}

The precision spindle system of the 170CP06 is mainly composed of the spindle,case,belt pulley,bearing cover and the angular contact ball bearings,etc.The motor drives by a belt pulley mounted on the shaft to provide a driving force for the spindle. The main parameters of the spindle is:

Its material is alloy Steel.The total length is $497 \mathrm{~mm}$. The maximum diameter of the spindle is $\phi 100 \mathrm{~mm}$. The rated speed of the spindle system is $4500 \mathrm{r} / \mathrm{min}$. The maximum power is $35 \mathrm{~kW}$ and the maximum torque is 180 N.m.Fig. 1 is the structure diagram for spindle system.

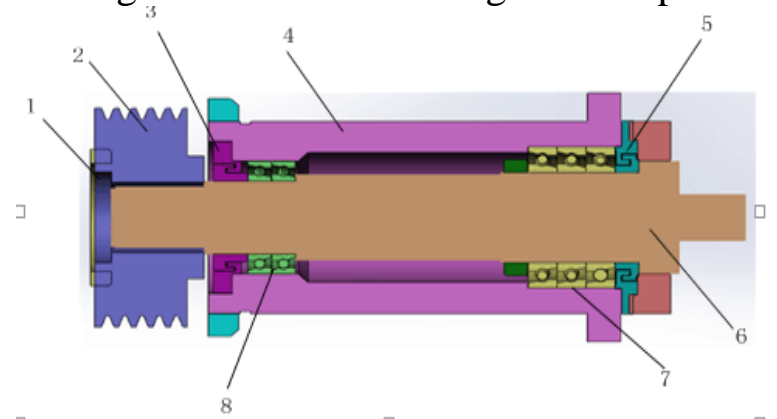

1-Big nut 2-Belt pulley 3-Left cover 4-Case 5-Right cover 6-Spindle

7-Fore bearing 8-Rear bearing

Fig.1 Structure diagram for spindle system

The model of the spindle system is established by using the three-dimensional mapping software-SoildWorks.And it simplifies appropriately the structure that influences analysis results less.According to the spindle of the boundary conditions and heat transfer characteristics,Simplified solid model is introduced to the finite element analysis software to be meshing of the grid $^{[12]}$.Fig.2 is a simplified and meshing model of the spindle system. The entire model has 128,143 units and 232,855 nodes.

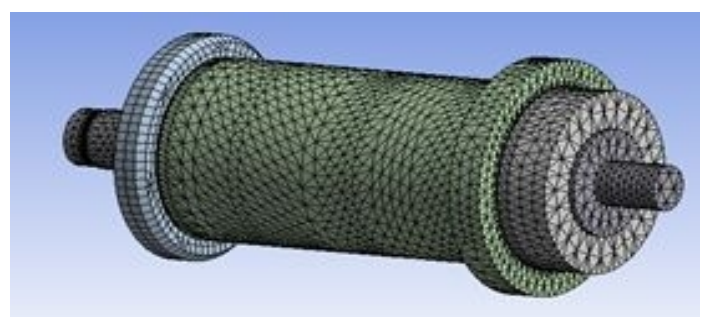

Fig.2 Meshing of the spindle system 


\section{Simulation analysis of the spindle system's temperature field}

The thermal analysis is established in the software of finite element analysis. The material of the spindle and bearing are defined as alloy steel.The ambient temperature is $26^{\circ} \mathrm{C}$.According to the boundary conditions of the spindle and the characteristics of the heat transfer, the heat generation rate of the fore and rear bearings is $342704.4 \mathrm{~W} / \mathrm{m}^{3}$ and $348161.76 \mathrm{~W} / \mathrm{m}^{3}$ which are applied to the fore and rear bearings. The coefficients of the heat transfer convection are added to the respective member surface spindle system as boundary conditions.It is conducted the steady-state and transient thermal analysis of the spindle system.

\section{The analysis of the steady temperature field}

When the spindle speed is $2000 \mathrm{r} / \mathrm{min}$, we can get the simulation of the steady-state temperature field resulting in the steady-state temperature field contour of the spindle system. As is shown in Fig.3.

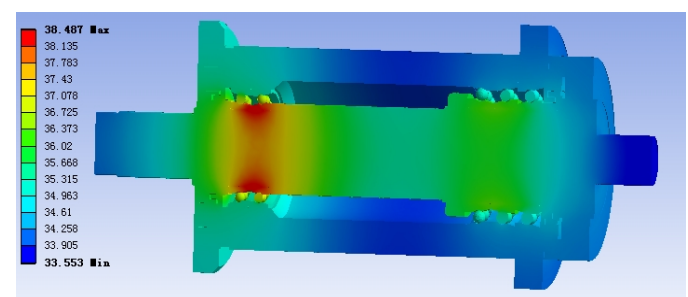

Fig.3 Steady-state temperature distribution of spindle system

Fig. 3 shows that the maximum temperature of the spindle system appears at the inner ring of the rear bearing.Its temperature is $38.5^{\circ} \mathrm{C}$. The maximum temperature rise is $12.5^{\circ} \mathrm{C}$. The heat of the rear bearing is larger than the fore bearing. And it is caused by the poor cooling condition of the inner ring. The analysis of the transient temperature field

When the spindle system is the analysis of the transient temperature field to get the bearing temperature curve and the thermal equilibrium time by setting the operating time of $65 \mathrm{~min}$. Fig. 4 are the contours of the temperature field at different time points.

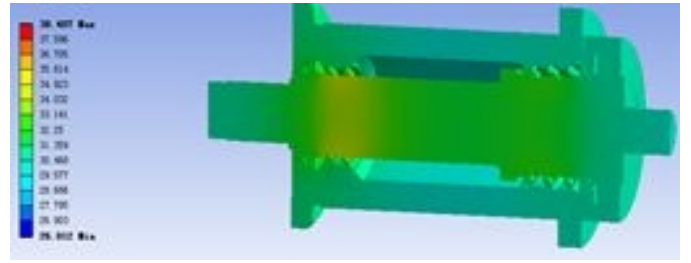

$1600 s$

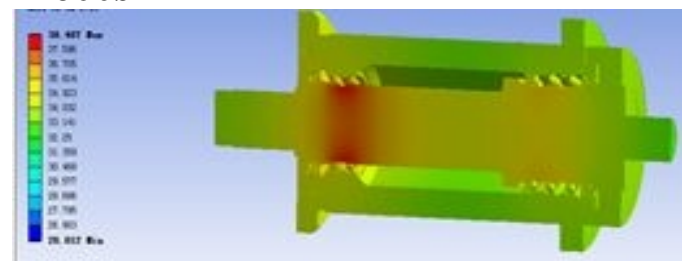

3200s

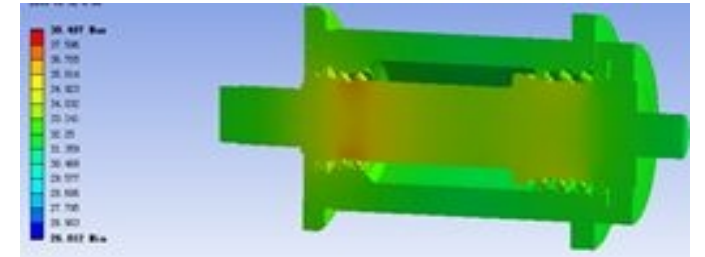

2400s

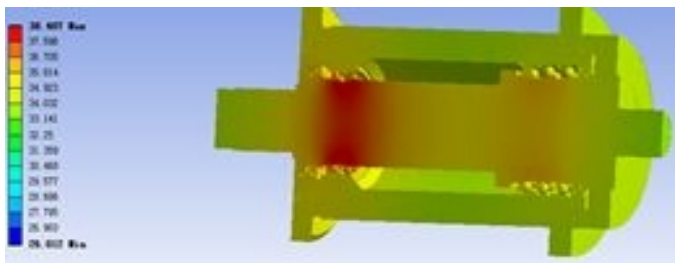

$3600 s$

Fig.4 Contours of the temperature field at different time points

The spindle system has reached the thermal equilibrium after running 60min.The highest temperatures of the fore bearing and rear bearing are $34.19^{\circ} \mathrm{C}$ and $35.9^{\circ} \mathrm{C}$.

\section{Experimental test}

The automatic test system of mechanical spindle characteristic is used for the temperature rise test which is in the status of the of mechanical spindle torque output, the load and without load at each speed.The test system consists of the machine base, torque and speed sensors, industrial computer,ervo motor,multi-channel temperature control instrument and so on. The test principle is that the spindle connects the arrester detent via couplings, torque and speed sensor and the motor drives by a belt drive to make the spindle rotate by changing the brake excitation current method to the load control 
for the spindle system.Fig.5 is the operating principle of the experiment platform.Fig.6 is the experiment device of mechanical spindle system.

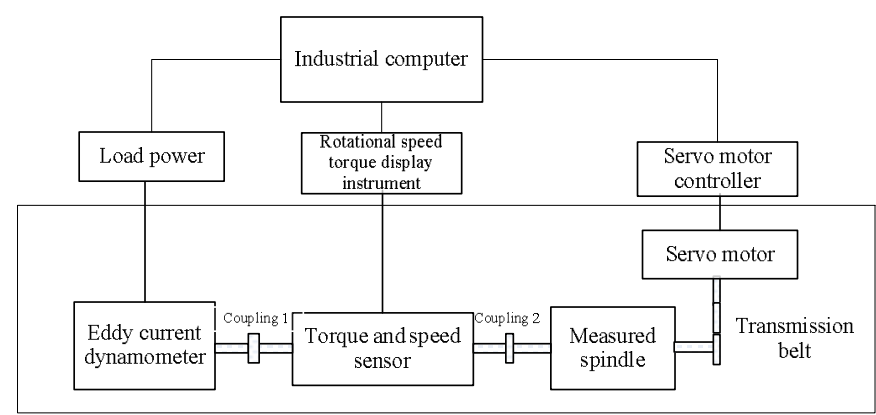

Fig.5 Operating principle of the experiment platform

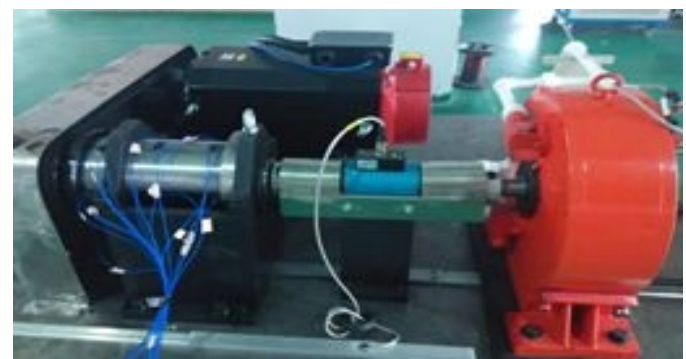

Fig.6 The experiment device of mechanical spindle system

The temperature sensors are disposed with in the outer ring of the fore and rear bearings, the rear end surface of the rear bearing and and outer surface of the case.Fig. 7 is the distribution of test points. At the speed of $2000 \mathrm{r} / \mathrm{min}$ and $4500 \mathrm{r} / \mathrm{min}$, the spindle system is testing temperature rise the without load.When the spindle system has reached the equilibrium, we can measure the temperature of each of the key parts.We will take test point 2 and test point 8 for example and can see the changes in the bearing temperature with time.Fig. 8 is the temperature rise curve for test point 2 and 8 at the speed of 2000r/min and 4500r/min.

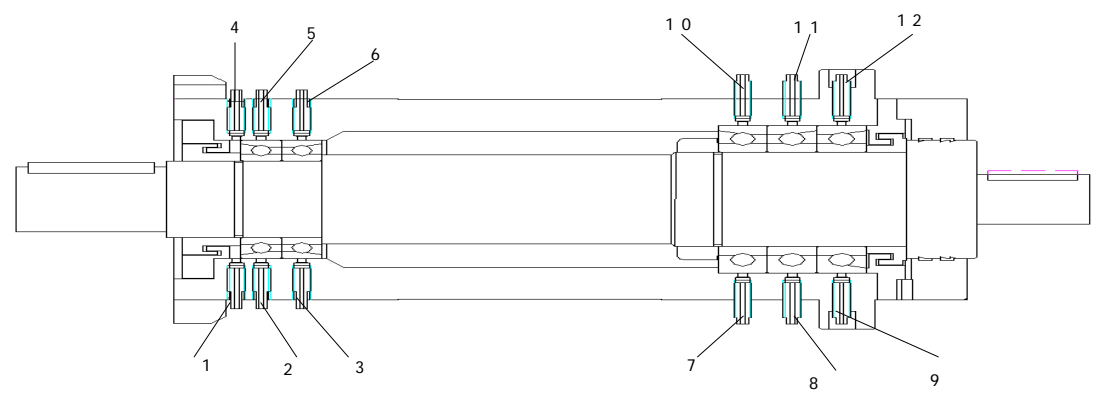

Fig.7 The distribution of test points 

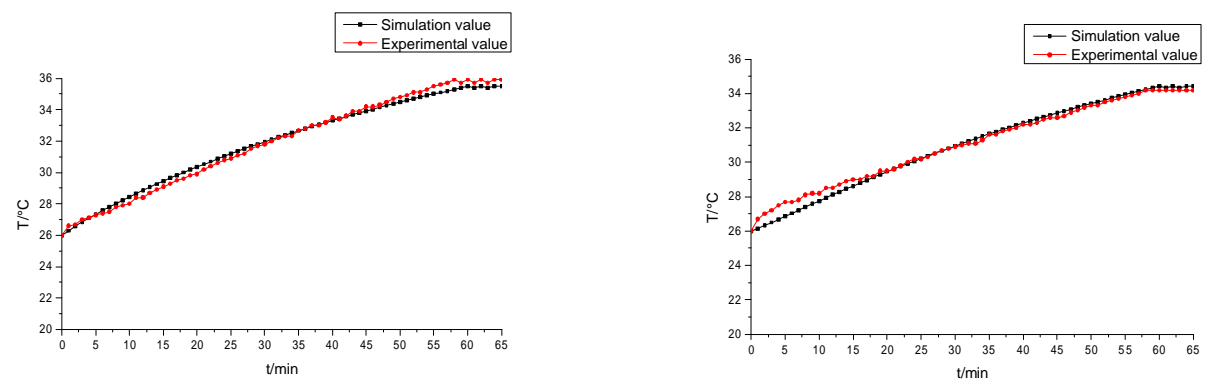

a. The temperature of test point 2 (Speed of $2000 \mathrm{r} / \mathrm{min}$ )

b. The temperature of test point 8(Speed of 2000r/min)
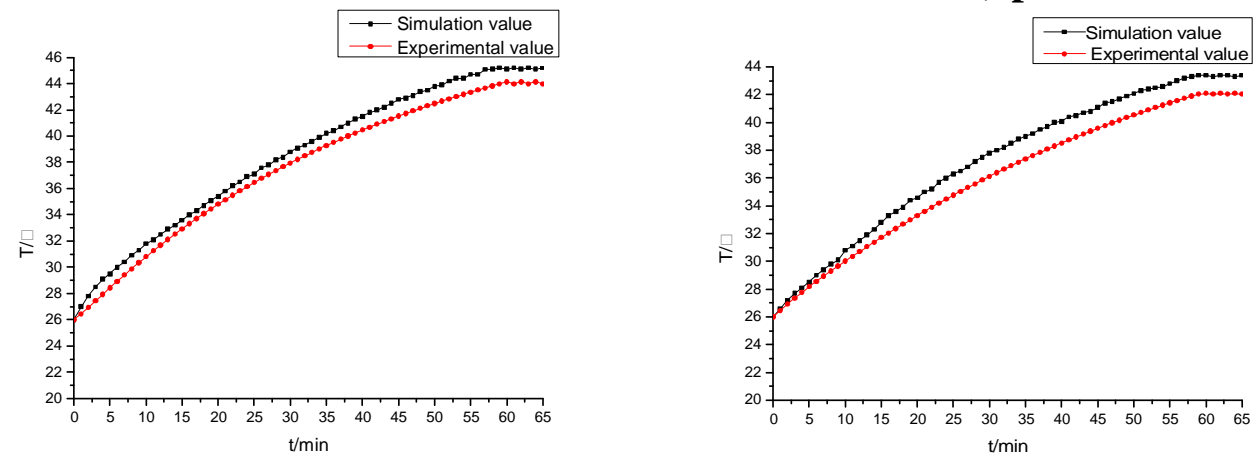

c. The temperature of test point 2 (Speed of $4500 \mathrm{r} / \mathrm{min})$

d. The temperature of test point 8(Speed of 4500r/min)

Fig. 8 Temperature rise curve for test point 2 and 8 (Speed of $2000 \mathrm{r} / \mathrm{min}$ and $4500 \mathrm{r} / \mathrm{min}$ )

As can be seen from Fig.8, we can see that there are some errors compared with experimental data and simulation data.But there is the same upward trend basically that explains the model is reliable. When the spindle speed is $2000 \mathrm{r} / \mathrm{min}$ and the system has been running for $60 \mathrm{mins}$, the system has reached steady state temperature. And the highest temperatures of test point 2 and 8 are $34.19^{\circ} \mathrm{C}$ and $35.9^{\circ} \mathrm{C}$. There are more obvious changes of the temperature rise when the spindle system is running at the beginning. The temperature rise changes smaller after $55 \mathrm{~min}$ and reaches steady state about $57.5 \mathrm{~min}$. When the spindle speed is $4500 \mathrm{r} / \mathrm{min}$, the spindle system rises faster before $52.5 \mathrm{~min}$ and reaches equilibrium about $55 \mathrm{~min}$. Next, we will test the temperature rise when the spindle speed are $1000 \mathrm{r} / \mathrm{min}, 1500 \mathrm{r} / \mathrm{min}, 2500 \mathrm{r} / \mathrm{min}, 3000 \mathrm{r} / \mathrm{min}, 3500 \mathrm{r} / \mathrm{min}$ and $4000 \mathrm{r} / \mathrm{min}$. As the key parts of the test points 2 and 8 for example, We can obtain the maximum temperature of each test point under different speeds as shown in Fig.9.

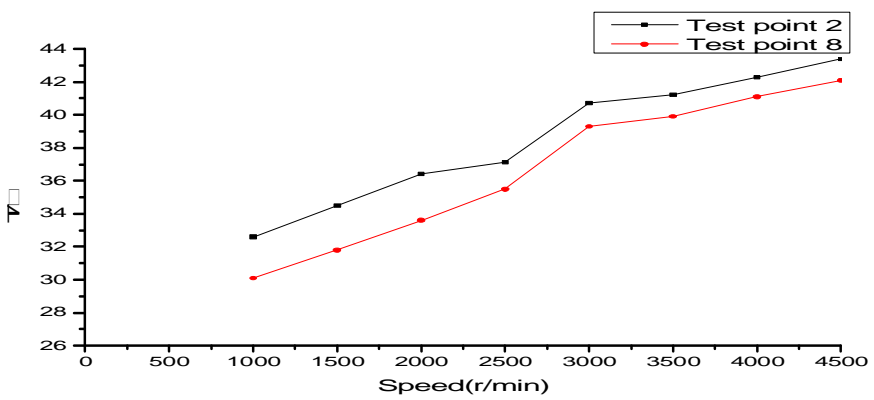

Fig.9 Spindle temperature at different speeds

As can be seen from Fig.9, as the spindle speed increases, the temperature rise of the bearings is more and more higher.And the test point 2 is slightly higher than the test point 8 . When the spindle speed changes 1000 to $3000 \mathrm{r} / \mathrm{min}$, the bearing temperature changes more obviously. The change of the temperature is flat relatively when the spindle speed changes 3000 to $4500 \mathrm{r} / \mathrm{min}$. 


\section{Conclusion}

In this paper, it is conducted the thermal analysis of the spindle system combining the method of the finite element analysis with experimental verification and resulting in the following conclusions: (1) The above analysis shows that the simulation model of the machine spindle is reliable. The result of errors is less than $3 \%$ compared the simulation data with the experimental data.

(2) When the spindle speed is changing 1000 to $3000 \mathrm{r} / \mathrm{min}$, the temperature of bearings have changed more obviously. The change of the temperature is flat relatively when spindle speed is changing 3000 to $4500 \mathrm{r} / \mathrm{min}$.It indicates that the speed impacts the temperature greater under low speeds. And for the high speed,the temperature is impact to the speed relatively small.For the spindle,which is the rated speed of $4500 \mathrm{r} / \mathrm{min}$, the temperature changes rapidly under its two-thirds' rated speed. While the speed is more than two-thirds' rated speed, the temperature changes slowly.

(3) The spindle system has reached the different thermal equilibrium time at different spindle speeds. The higher the speed is, the shorter the spindle has reached thermal equilibrium time.

(4) The precision spindle of $170 \mathrm{CP} 06$ has reached the thermal equilibrium at rated speed for $55 \mathrm{~min}$. The highest temperature is $45.2^{\circ} \mathrm{C}$ that occurs to the bear bearing.

\section{References}

[1] D.A.Krulewich,Temperature integration model and measurement point selection for thermally induced machine tool errors, Mechantronics, 1998,8:395 412.

[2] Zhen Zhu,Penghao $\mathrm{Hu}, \mathrm{Yi}$ Tao.The analysis of three-dimensional spindle temperature field and thermal deformation[J]. Tool technology,2008(4):66-68.

[3] Choi jin-Kyung,Lee Dai-Gil.Thermal-characteristics of the spindle bearing system with a gear located on the bearing $[\mathrm{J}]$.

[4] M.H.Attia,L.Kops,Computer simulation of nonlinear thermoPlastie behavior of a joint in maehine tool structure and its effeet on thermal deformation,Transaetions of the ASME,Journal of Enginnering fo rIndustry,101(1979)355-361.

[5] Ce Guo,Qinghong Sun.The thermal-characteristics' analysis of the high-speed and high-precision CNC lathe spindle system and thermal deformation.Journal of Southeast University, 2005,35 (2).

[6] Wen Peng,Youwei Hong.The thermal-characteristics numerical analysis of five-axis gantry machining center 's spindle system [J]. Modular Machine Tool \& Automatic Manufacturing Technique. 2005 (08).

[7] Xingjuan Ying, Haolin Li .The finite element analysis of CNC machine tool spindle's system thermal characteristics [J] tool technology, 2010,4 (1): 38-40.

[8] Datong Qin.Bearing. Beijing: Chemical Industry Press .2013.3 (5).

[9] Xinsheng Li Bobao Zhao, Yaping. The thermal simulation analysis of high-speed spindle [J] tool technology, 2012 (4): 64-32.

[10] F.P.Incropera, D.P.DeWitt,T.L.Bergman. Fundamentals of Heat and Mass Transfer [M] .2012.

[11] Chongzhi Guo,Le Xiao.A sequence coupling method for numerical simulation of temperature [J]. Chemical Industry and Engineering Progress. 2010 (09).

[12] Shiming Yang,Wenquan Tao,Heat Transfer [M] Beijing: Higher Education Press, 1998.

[13] Xiangqian Kong.The finite element method in heat transfer.Beijing: Science Press, 1986.

[14] Can Zhou, Yuhui He,Guiling Deng.The transient temperature field analysis and testing of high-speed spindle[J].Computer Simulation, 2012,29 (2): 372-377. 